Neil V. Morgan · Paul Gissen · Saghira Malik Sharif

Laura Baumber · Joan Sutherland · Deirdre A. Kelly

Kingi Aminu $\cdot$ Christopher P. Bennett

C. Geoffrey Woods · Robert F. Mueller

Richard C. Trembath · Eamonn R. Maher

Colin A. Johnson

\title{
A novel locus for Meckel-Gruber syndrome, MKS3, maps to chromosome 8q24
}

Received: 12 June 2002 / Accepted: 12 July 2002 / Published online: 7 September 2002

(C) Springer-Verlag 2002

\begin{abstract}
Meckel-Gruber syndrome (MKS), the most common monogenic cause of neural tube defects, is an autosomal recessive disorder characterised by a combination of renal cysts and variably associated features, including developmental anomalies of the central nervous system (typically encephalcoele), hepatic ductal dysplasia and cysts, and polydactyly. Locus heterogeneity has been demonstrated by the mapping of the MKS1 locus to $17 q 21-24$ in Finnish kindreds, and of $M K S 2$ to $11 \mathrm{q} 13$ in North African-Middle Eastern cohorts. In the present study, we have investigated the genetic basis of MKS in eight consanguineous kindreds, originating from the Indian sub-continent, that do not show linkage to either $M K S 1$ or $M K S 2$. We report the localisation of a third MKS locus $(M K S 3)$ to chromosome $8 \mathrm{q} 24$ in this cohort by a genome-wide linkage search using autozygosity mapping.
\end{abstract}

Electronic Supplementary Material is available if you access this article at http://dx.doi.org/10.1007/s00439-002-0817-0. On that page (frame on the left side), a link takes you directly to the supplementary material.

N.V. Morgan · P. Gissen · E.R. Maher · C.A. Johnson ( $\bowtie)$ Section of Medical and Molecular Genetics,

Department of Paediatrics and Child Health,

University of Birmingham Medical School,

Birmingham, B15 2TT, UK

e-mail: c.a.johnson@bham.ac.uk

P. Gissen · D.A. Kelly

Children's Liver Unit, Princess of Wales Children's Hospital,

Steelhouse Lane, Birmingham, B4 6NH, UK

S.M. Sharif · C.P. Bennett · C.G. Woods · R.F. Mueller

Department of Clinical Genetics,

Yorkshire Regional Genetics Service,

St. James's University Hospital, Beckett Street, Leeds, LS9 7TF, UK

L. Baumber · J. Sutherland · K. Aminu · R.C. Trembath

Division of Medical Genetics,

Departments of Medicine and Genetics, University of Leicester, Leicester, LE1 7RH, UK

R.F. Mueller

Molecular Medicine Unit, University of Leeds,

St. James's University Hospital, Leeds, LS9 7TF, UK
We identified a 26-cM region of autozygosity between D8S586 and D8S1108 with a maximum cumulative twopoint LOD score at D8S1179 $\left(Z_{\max }=3.04\right.$ at $\left.\theta=0.06\right)$. A heterogeneity test provided evidence of one unlinked family. Exclusion of this family from multipoint analysis maximised the cumulative multipoint LOD score at locus D8S1128 $\left(Z_{\max }=5.65\right)$. Furthermore, a heterozygous SNP in $D D E F 1$, a putative candidate gene, suggested that MKS3 mapped within a 15-cM interval. Comparison of the clinical features of $M K S 3$-linked cases with reports of $M K S 1$ - and MKS2-linked kindreds suggests that polydactyly (and possibly encephalocele) appear less common in MKS3-linked families. Electronic Supplementary Material is available if you access this article at http:// dx.doi.org/10.1007/s00439-002-0817-0. On that page (frame on the left side), a link takes you directly to the supplementary material.

\section{Introduction}

Autosomal recessive disorders represent an important cause of morbidity and mortality, particularly within the paediatric age range. A number of autosomal recessive conditions reach significant frequency within specific populations and ethnic groups. In Britain this is particularly true for some communities of Indian sub-continent origin, in which consanguinity is frequent (Bundey and Alam 1993). Meckel-Gruber syndrome [MKS (MIM 249000)] is an autosomal recessive lethal malformation syndrome characterised by large multicystic kidneys, central nervous system malformations (classically prosencephalic dysgenesis, occipital encephalocele and rhombic roof dysgenesis), bilateral upper and lower limb postaxial polydactyly and fibrocystic changes of the liver (AhdabBarmada and Claassen 1990; Salonen and Paavola 1998). Phenotypic expression is variable, but renal involvement appears to be a consistent finding (Fraser and Lytwyn 1981; Salonen 1984). In addition, hepatic developmental defects (e.g. arrested development of the intrahepatic biliary system and ductal plate malformations) are usually 
present if sought (Blankenberg et al. 1987). Survival beyond the perinatal period is unusual. Estimates of the population frequency of MKS vary between 1:13,250 in the USA (Holmes et al. 1976) and 1:140,000 in Great Britain (Seller 1978), whilst higher frequencies have been reported in Finland and North Africa, 1:9,000 and 1:3,500, respectively (Salonen and Paavola 1998). MKS is considered the most frequent syndromic cause of neural tube defects (Simpson et al. 1991).

Locus heterogeneity has been documented previously for MKS. Linkage analysis of a cohort of Finnish MKS kindreds identified a locus (MKS1) at 17q21-24 (Paavola et al. 1995). Autozygosity mapping studies using inbred families from the Middle East and North Africa revealed a second locus, $M K S 2$, at chromosome $11 \mathrm{q} 13$ with additional families evidently not linked to either locus (Roume et al. 1998). MKS1 or MKS2 genes at these loci have not been identified. We now report the mapping of a further locus $(M K S 3)$ to chromosome $8 \mathrm{q} 24$ in consanguineous families that originate from Pakistan and Northern India, and present evidence of yet further genetic heterogeneity in this disorder.

\section{Patients and methods}

Patients

Eight consanguineous MKS families from Pakistan and Northern India were ascertained through the West Yorkshire, West Midlands and Leicestershire Regional Clinical Genetics Services. Seven families originated from Pakistan and the remaining family $(\mathrm{H})$, with two affected siblings, was from the Gujarat region of Northern India. Anonymised pedigrees of the families are shown in Fig. 1. DNA was available from parents, affected probands and unaffected siblings as shown in Fig. 1. In eight of nine probands, a therapeutic termination of pregnancy was performed following an ultrasound diagnosis of MKS during the second trimester of pregnancy (Silva and Jeantry 2000). One affected foetus was stillborn at 30 weeks. Prior to the start of the study, a diagnosis of MKS was confirmed by an experienced clinical geneticist (R.F.M., C.P.B.) following autopsy. All affected cases had cystic dysplasia of the kidneys and a normal cultured skin fibroblast karyotype. Informed consent was obtained from families and the study was approved by the relevant local research ethics committees (LRECs).

\section{Molecular genetic studies}

DNA was isolated from blood and frozen tissue by standard techniques (Müllenbach et al. 1989). Linkage to MKS1 and MKS2 was
Fig. 1 Pedigrees of eight consanguineous MKS families from Pakistan and Northern India (denoted $A-H$ ). Affected probands are shaded
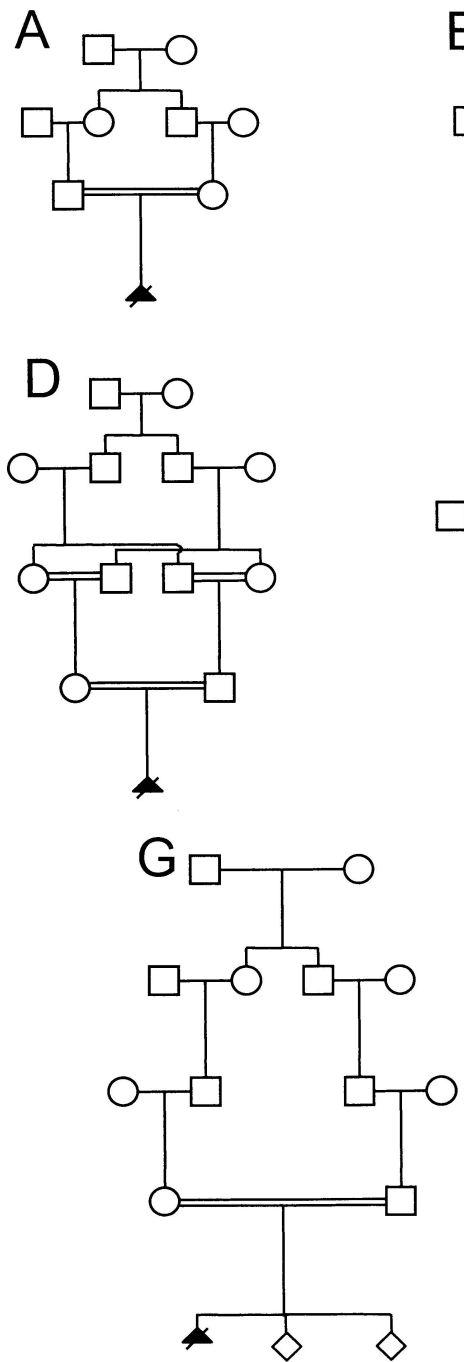
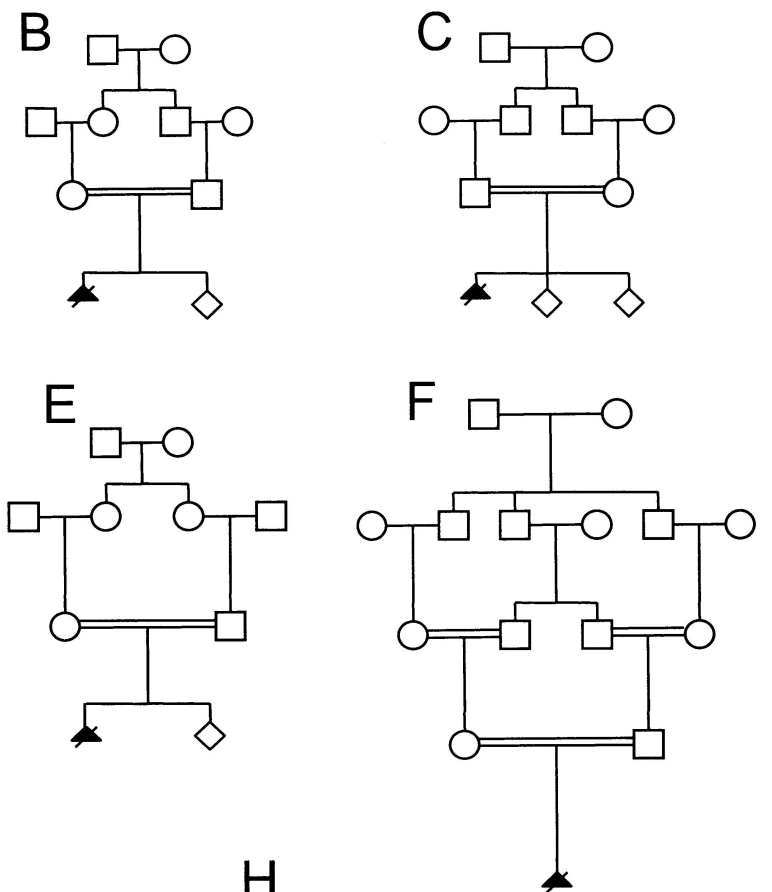

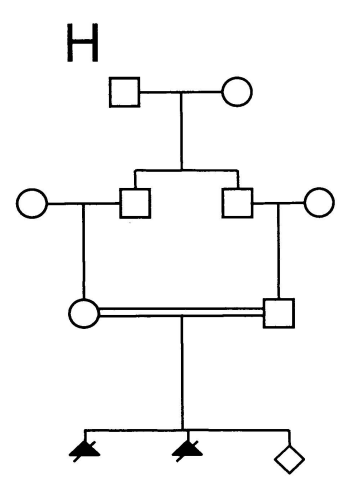


excluded by the finding of heterozygosity with microsatellite markers spanning $M K S 1$ and $M K S 2$ (see later) before a genomewide linkage screen was undertaken, with 200 fluorescently labelled microsatellite markers from the Research Genetics version 10 mapping panel. PCR amplifications were performed using standard methods. PCR products were analysed on an ABI 377 DNA Analyzer and Genescan v3.1.2 and Genotyper v2.5.2 software (Applied Biosystems). The initial genome-wide screen used only affected probands.

Mutation analysis of candidate genes

Two genes mapping within the $M K S 3$ target region were selected for mutation analysis. Primers were designed from the NOVH (also known as $N O V$ ) genomic clone X78351-54 (GenBank) and the DDEF1 BACs AC019167 and AC009682, from intronic sequences surrounding the exons. Primer sequences for the PCR products that span the five coding exons of NOVH and the 21 coding exons of $D D E F 1$ are available as electronic supplementary information from the website for this journal (http://link.springer. de). PCR products from proband samples were sequenced with a BigDye Terminator Cycle Sequencing Kit on an ABI 377 DNA Analyzer (Applied Biosystems).

Statistics

Two-point LOD scores were calculated with the LINKAGE (version 5.1) software package (Cottingham et al. 1993), assuming a fully penetrant autosomal recessive gene with a disease allele frequency of 0.001. Alleles for marker loci were assumed to be codominant and to occur at equal frequencies, because population allele frequencies were not available. Multipoint LOD scores were calculated using LINKMAP (version 5.1) software, again with assumption of equal allele frequencies.

\section{Results}

Exclusion of linkage to $M K S 1$ and $M K S 2$

Eight nuclear families were typed with microsatellite markers spanning MKS1 (D172180, D171606, D17S1290,

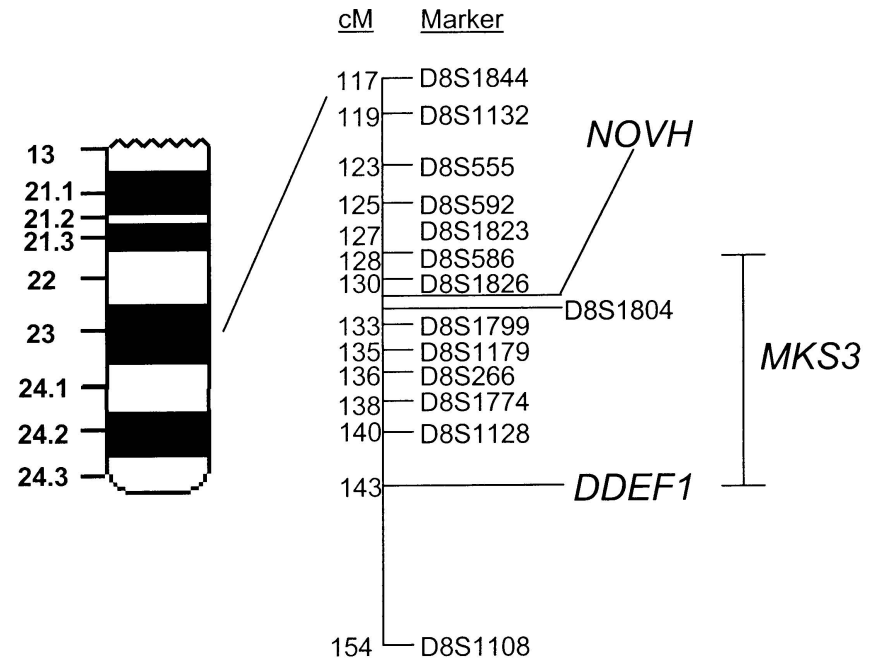

Fig. 2 Linkage map of microsatellite markers at chromosome 8q23-24. The locations of two candidate genes, NOVH and $D D E F 1$ are indicated. Approximate genetic distances in centiMorgans $(\mathrm{cM})$ of the markers are taken from the Marshfield genetic map
D17S807, D17S2193, D17S1301 and D17S2195) over 40 cM and MKS2 (D11S2006, D11S2371, D11S4079, D11S937, D11S2002 and D11S2000) over $42 \mathrm{cM}$. In each kindred there was no evidence of linkage to either $M K S 1$ or $M K S 2$, with cumulative two-point LOD scores $Z<-2$ for all spanning markers (data not shown).

\section{Genome-wide linkage screen}

After linkage to $M K S 1$ and $M K S 2$ was excluded, we performed a genome-wide search in the eight affected probands with 200 microsatellite markers, at an average spacing of $20 \mathrm{cM}$. At this stage, a region of homozygosity on chromosome 8q24 was apparent. Fourteen microsatellite

Table 1 Cumulative two-point LOD scores for the MKS3 locus in a cohort of eight Pakistani and Northern Indian families with markers from chromosome 8q24

\begin{tabular}{|c|c|c|c|c|c|c|}
\hline \multirow[t]{2}{*}{ Locus } & \multicolumn{6}{|c|}{ LOD score at $\theta=$} \\
\hline & Family & 0.00 & 0.050 & 0.100 & 0.200 & 0.300 \\
\hline \multirow[t]{9}{*}{ D8S1804 } & A & 0.598 & 0.506 & 0.417 & 0.258 & 0.135 \\
\hline & $\mathrm{B}$ & 0.848 & 0.712 & 0.581 & 0.348 & 0.176 \\
\hline & $\mathrm{C}$ & $-\infty$ & -0.165 & 0.004 & 0.071 & 0.057 \\
\hline & $\mathrm{D}$ & 0.641 & 0.535 & 0.435 & 0.260 & 0.132 \\
\hline & $\mathrm{E}$ & 0.422 & 0.352 & 0.285 & 0.170 & 0.086 \\
\hline & $\mathrm{F}$ & -1.251 & -0.495 & -0.286 & -0.114 & -0.045 \\
\hline & $\mathrm{G}$ & -1.344 & -0.360 & -0.170 & -0.044 & -0.009 \\
\hline & $\mathrm{H}$ & $-\infty$ & -0.620 & -0.365 & -0.156 & -0.068 \\
\hline & Total & $-\infty$ & 0.464 & 0.901 & 0.793 & 0.463 \\
\hline \multirow[t]{9}{*}{ D8S1799 } & A & 0.630 & 0.535 & 0.443 & 0.277 & 0.146 \\
\hline & $\mathrm{B}$ & 0.454 & 0.381 & 0.311 & 0.188 & 0.096 \\
\hline & $\mathrm{C}$ & 0.454 & 0.381 & 0.311 & 0.188 & 0.096 \\
\hline & $\mathrm{D}$ & 0.762 & 0.631 & 0.508 & 0.294 & 0.142 \\
\hline & $\mathrm{E}$ & 0.444 & 0.370 & 0.300 & 0.172 & 0.075 \\
\hline & $\mathrm{F}$ & 0.762 & 0.631 & 0.508 & 0.294 & 0.142 \\
\hline & $\mathrm{G}$ & -1.302 & -0.536 & -0.318 & -0.131 & -0.053 \\
\hline & $\mathrm{H}$ & $-\infty$ & -1.299 & -0.763 & -0.310 & -0.117 \\
\hline & Total & $-\infty$ & 1.096 & 1.300 & 0.971 & 0.526 \\
\hline \multirow[t]{9}{*}{ D8S1179 } & A & 0.695 & 0.596 & 0.498 & 0.318 & 0.171 \\
\hline & B & 0.820 & 0.679 & 0.543 & 0.302 & 0.127 \\
\hline & $\mathrm{C}$ & 0.644 & 0.555 & 0.466 & 0.300 & 0.163 \\
\hline & $\mathrm{D}$ & 0.882 & 0.745 & 0.611 & 0.371 & 0.188 \\
\hline & $\mathrm{E}$ & 0.983 & 0.840 & 0.700 & 0.442 & 0.235 \\
\hline & $\mathrm{F}$ & -1.304 & -0.277 & -0.092 & 0.013 & 0.023 \\
\hline & G & 1.189 & 1.008 & 0.829 & 0.498 & 0.240 \\
\hline & $\mathrm{H}$ & $-\infty$ & -1.139 & -0.655 & -0.267 & -0.103 \\
\hline & Total & $-\infty$ & 3.005 & 2.901 & 1.977 & 1.043 \\
\hline \multirow[t]{9}{*}{ D8S266 } & A & 0.620 & 0.526 & 0.435 & 0.271 & 0.142 \\
\hline & B & 0.897 & 0.758 & 0.624 & 0.381 & 0.197 \\
\hline & $\mathrm{C}$ & 0.583 & 0.498 & 0.415 & 0.262 & 0.140 \\
\hline & $\mathrm{D}$ & 0.744 & 0.615 & 0.493 & 0.283 & 0.136 \\
\hline & $\mathrm{E}$ & 0.745 & 0.640 & 0.536 & 0.345 & 0.187 \\
\hline & $\mathrm{F}$ & -1.291 & -0.318 & -0.130 & -0.013 & 0.008 \\
\hline & $\mathrm{G}$ & 0.091 & 0.010 & 0.093 & 0.063 & 0.033 \\
\hline & $\mathrm{H}$ & $-\infty$ & -1.216 & -0.708 & -0.281 & -0.101 \\
\hline & Total & $-\infty$ & 1.603 & 1.758 & 1.310 & 0.743 \\
\hline
\end{tabular}


Table 2 Genotypes in affected individuals of markers spanning the MKS3 locus on chromosome 8q23-24 (n.t. not tested)

\begin{tabular}{|c|c|c|c|c|c|c|c|c|c|c|c|c|c|c|c|c|c|c|c|}
\hline $\mathrm{cM}$ & \multicolumn{19}{|c|}{ Family proband } \\
\hline 117 & D8S1844 & 4 & 4 & 4 & 4 & 2 & 2 & 6 & 1 & 1 & 1 & 4 & 1 & 6 & 6 & 1 & 2 & n.t. & n.t. \\
\hline 119 & D8S1132 & 2 & 2 & 7 & 7 & 5 & 5 & 6 & 4 & 3 & 3 & 3 & 3 & n.t. & n.t. & 8 & 6 & n.t. & n.t. \\
\hline 123 & D8S555 & 7 & 7 & 7 & 7 & 5 & 5 & 5 & 4 & 4 & 4 & 5 & 5 & 5 & 5 & 5 & 2 & n.t. & n.t. \\
\hline 125 & D8S592 & 3 & 3 & 3 & 3 & 2 & 2 & 2 & 3 & 3 & 3 & 1 & 2 & 2 & 2 & 2 & 2 & n.t. & n.t. \\
\hline 130 & D8S1826 & 11 & 11 & 12 & 12 & 11 & 11 & 11 & 11 & 10 & 10 & 10 & 11 & 12 & 12 & 11 & 10 & 12 & 12 \\
\hline 132 & D8S1804 & 1 & 1 & 3 & 3 & 2 & 2 & 1 & 1 & 5 & 5 & 4 & 1 & n.t. & n.t. & 1 & 1 & 4 & 1 \\
\hline 133 & D8S1799 & 20 & 20 & 9 & 9 & 20 & 20 & 15 & 15 & 19 & 19 & 9 & 9 & n.t. & n.t. & 9 & 9 & 15 & 15 \\
\hline 135 & D8S1179 & 7 & 7 & 3 & 3 & 8 & 8 & 8 & 8 & 4 & 4 & 3 & 6 & 5 & 5 & 8 & 5 & 5 & 6 \\
\hline 136 & D8S266 & 6 & 6 & 3 & 3 & 4 & 4 & 6 & 6 & 6 & 6 & 4 & 7 & n.t. & n.t. & 7 & 5 & n.t. & n.t. \\
\hline 138 & D8S1774 & 16 & 16 & 15 & 15 & 15 & 15 & 16 & 16 & 15 & 15 & 3 & 16 & n.t. & n.t. & 13 & 16 & n.t. & n.t. \\
\hline
\end{tabular}

markers (see Fig. 2) mapping to 8q23-24 were genotyped to further investigate the candidate region. Markers were analysed in all available family members (probands, in addition to unaffected parents and siblings) in order to phase haplotypes. Significant linkage was detected at $\operatorname{D8S1179}\left(Z_{\max }=3.04\right.$ at $\theta=0.06$; refer to Table 1$)$. Genotype results for each proband are shown in Table 2. Genotypes for kindred C placed the $M K S 3$ locus in a $28-\mathrm{cM}$ interval between D8S586 and D8S1108. The Smith admixture test (Smith 1963) was performed to test for heterogeneity. The estimated proportion of families consistent with linkage to 8q23-24 was 0.70. Rejection of homogeneity was mainly due to kindred $\mathrm{H}$, since $Z<-2$ for all markers in the critical interval (see Tables 1 and 2), and each affected sibling had different haplotypes. This excludes linkage of kindred $\mathrm{H}$ to the $M K S 3$ locus. To provide details on the likely location of $M K S 3$, we excluded family $\mathrm{H}$ and performed a multipoint analysis. A maximum cumulative multipoint LOD score was obtained at locus D8S1128 $\left(Z_{\max }=5.65\right.$; Fig. 3$)$. Family $\mathrm{F}$ showed a small region of autozygosity at D8S1799 that needs further investigation, as it would significantly reduce the MKS critical interval. Inspection of haplotypes in families A to $G$ did not show evidence of a founder mutation (Table 2). For marker D8S586, homozygous alleles were found to be common to three families (A, B and D). Allele 11 for marker D8S1826 was homozygous and common to families A, C and D; allele 12 was homozygous in two other families, and family $\mathrm{H}$ which is unlinked to $M K S 3$ (Table 2).

\section{Candidate gene analysis}

Two potential candidate genes, $N O V H$ (nephroblastoma overexpressed gene) and DDEF1 (development and differentiation enhancing factor 1 gene), were analysed for germline mutations. Sequencing of the five coding exons and adjacent splice sites of $N O V H$ did not reveal any se-

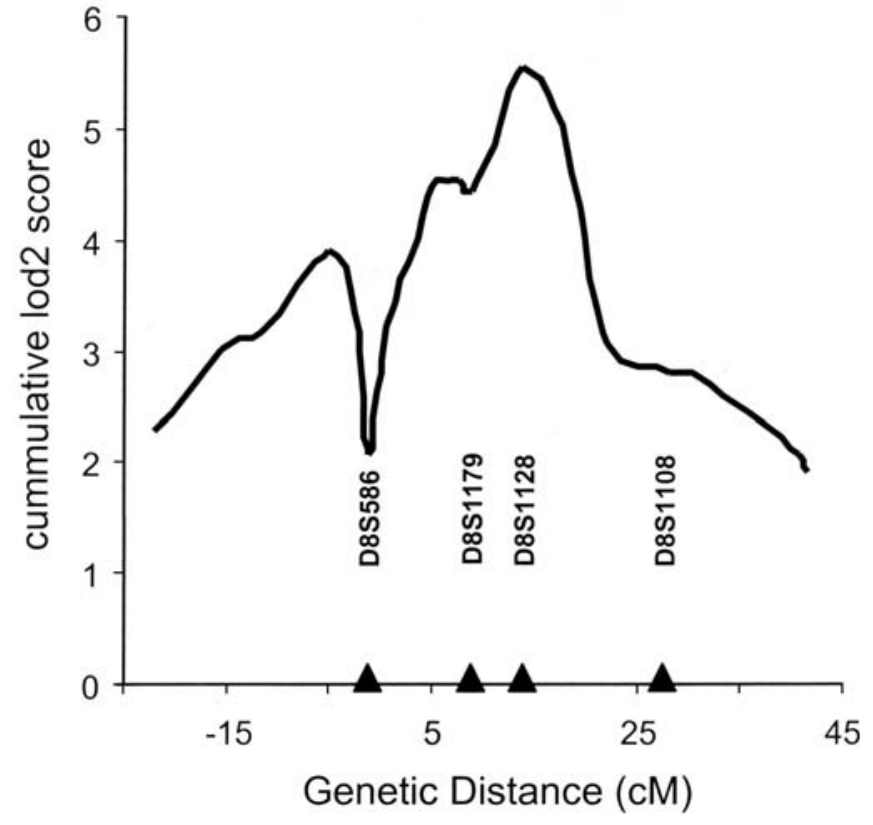

Fig. 3 Cumulative multipoint analysis of four chromosome 8 markers in MKS families. Family $\mathrm{H}$ was excluded from the analysis

quence variants. Sequence analysis of $D D E F 1$ revealed a single heterozygous SNP in intron 15 of the gene (IVS15-102 G>A), in the proband of family E. This suggested that the MKS3 locus mapped between D8S586 and $D D E F 1$, an interval of approximately $15 \mathrm{cM}$ (see Fig. 2).

\section{Discussion}

Autozygosity mapping in inbred families is a powerful strategy for localising recessive genes, even in the presence of locus heterogeneity (Lander and Botstein 1987; Mueller and Bishop 1993; Gschwend et al. 1996). In ad- 
dition to the mapping of MKS2 in North African and Middle-Eastern kindreds, Roume et al. (1998) reported one Tunisian kindred unlinked to either MKS1 or MKS2. To reduce the likelihood of locus heterogeneity in our cohort, we studied eight MKS families from the Indian sub-continent, in which linkage to $M K S 1$ and $M K S 2$ was excluded. Our results suggest that mutations in $M K S 3$ account for most cases of Meckel-Gruber syndrome within the British ethnic population that has originated from the Indian subcontinent, in which MKS is comparatively common (Young et al. 1986). We note that Roume et al. (1998) reported one MKS kindred linked to MKS2 that was of Pakistani origin, and we also report one kindred from Northern India (family $\mathrm{H}$ ) that did not show evidence of linkage to $M K S 1, M K S 2$ or $M K S 3$. This suggests that there may be further locus heterogeneity in both the Pakistani and Northern Indian populations.

MKS demonstrates marked intra- and inter-familial phenotypic variability. Although strict diagnostic criteria requiring the presence of a triad of major features (cystic kidneys, CNS malformation, usually occipital encphalocele, and polydactyly) have been proposed, in practice this definition is likely to be conservative. Comparison of probands and sibs in MKS kindreds revealed that, in general, sibs showed lesser degrees of malformation and that the only common feature in 65 patients was renal cystic dysplasia (Fraser and Lytwyn 1981). A similar conclusion was reached by Salonen (1984), but in addition, delayed development of the intrahepatic biliary tree (ductal plate malformation) also appeared to be a constant feature of MKS when the liver has been examined (Salonen 1984; Blankenberg et al 1987). In the study by Fraser and Lytwyn (1981), the criteria for selection of probands was renal cystic dysplasia, CNS malformation and at least one other anomaly known to occur in the syndrome. This study noted that the siblings of the probands had a broader phenotypic spectrum, with only $63 \%$ of siblings presenting with encephalocele (vs 89\% in the probands) and 55\% polydactyly (vs $85 \%$ in probands) (Fraser and Lytwyn 1981). Among the nine cases of our cohort, all had cystic dysplastic kidneys, seven had a CNS malformation (five of the seven with encephalocele) and one proband had polydactyly. In the MKSI-linked families described by Paavola et al. (1995), all had cystic dysplastic kidneys, a CNS malformation and polydactyly. The $M K S 2$-linked families that were reported by Roume et al. (1998) were selected for linkage analysis by the presence of a triad of classical CNS abnormalities (prosencephalic dysgenesis, occipital exencephalocele and rhombic roof dysgenesis); renal cystic dysplasia and polydactyly were also reported to be present in all cases. Although the incidence of CNS malformations and polydactyly is less in MKS3-linked cases than in MKS1and $M K S 2$-linked cases, it is not clear if this reflects differing criteria for selection for linkage studies, or a real genotype-phenotype correlation. Phenotypic overlap between MKS and other cerebro-acro-visceral syndromes has been observed (Brueton et al. 1990; Lurie et al. 1991; Walpole et al. 1991; Verloes et al. 1991), but no other similar disorder has been mapped at chromosome 8q.
We have mapped a novel disease locus, which we have termed $M K S 3$, to a $15-\mathrm{cM}$ interval between D8S586 and $D D E F 1$ at chromosome $8 \mathrm{q} 24$. There are $>50$ genes in the $M K S 3$ critical interval, and none of these appear obvious candidates for MKS. Among the genes that we have excluded as MKS3 are NOVH (nephroblastoma overexpressed) and DDEF1 (development and differentiation enhancing factor 1), which both map within the target interval for MKS3. NOVH is thought to have a role in the control of cell proliferation and has also been shown to bind extracellular matrix proteins such as fibulin 1C (Perbal et al. 1999). To assess NOVH as a candidate gene, we undertook mutation analysis by direct sequencing in the eight probands (see Materials an methods), but did not detect any sequence variants. However, sequencing of $D D E F 1$ revealed a heterozygous sequence change in the intronic sequence in one proband. Since all SNPs within the critical interval should be identical-by-descent, and hence homozygous, the MKS3 candidate region was reduced to $15 \mathrm{cM}$.

A functional role for mediating extracellular interactions by the MKS protein might be suggested by comparison with the putative functional roles of fibrocystin and nephrocystin. Fibrocystin, a putative receptor protein, is encoded by the gene mutated in autosomal recessive polycystic kidney disease (Ward et al. 2002), a monogenic fibrocystic syndrome similar to MKS. Nephrocystin, the product of the nephronophthisis type I gene (NPHPI), appears have a role in mediating cell adhesion (Hildebrandt and Omram 2001). Nephronophthisis, at least for the juvenile or type I form, manifests with cyst formation in the kidneys and occasional hepatic fibrosis, and therefore also resembles MKS.

The mapping of $M K S 3$ will enable molecular genetic testing to be offered to large families that can be confidently linked to $M K S 3$. This is particularly important for British families, as the phenotypic spectrum for MKS appears to be broad and could create problems in genetic counselling and prenatal diagnosis in the absence of a reliable diagnostic test. To narrow the critical interval we plan to ascertain and investigate additional families. The genotyping of further microsatellite markers and SNPs within the critical interval may identify evidence for a common ancestral haplotype in additional families. To date, no MKS genes have been identified and the identification of MKS3 will provide key insights into important developmental pathways, and may facilitate the identification of $M K S 1$ and $M K S 2$.

Acknowledgements The authors thank the families for their participation in this study, which was supported by the Wellcome Trust (UK Autozygosity Mapping Consortium: E.R.M., R.C.T., C.G.W. and R.F.M.), an Endowment Fund from Birmingham Children's Hospital Liver Unit (P.G. and C.A.J.) and a start-up grant from the Birth Defects Foundation (C.A.J.). We are grateful to a number of clinical colleagues for help in contacting families, including Dr. M. Barrow, Professor I. Young and Ms. S. Patel. 


\section{References}

Ahdab-Barmada M, Claassen D (1990) A distinctive triad of malformations of the central nervous system in the Meckel-Gruber syndrome. J Neuropathol Exp Neurol 49:610-620

Blankenberg TA, Ruebner BH, Ellis WG, Bernstein J, Dimmick JE (1987) Pathology of renal and hepatic anomalies in Meckel syndrome. Am J Med Genet (Suppl) 3:395-410

Brueton LA, Dillon MJ, Winter RM. (1990) Ellis-van creveld syndrome, Jeune syndrome, and renal-hepatic-pancreatic dysplasia: separate entities or disease spectrum? J Med Genet 27: 252-255

Bundey S, Alam H (1993) A five-year prospective study of the health of children in different ethnic groups, with particular reference to the effect of inbreeding. Eur J Hum Genet 1:206-219

Cottingham RW, Idury RM., and Schaffer AA (1993) Faster sequential genetic linkage computations. Am J Hum Genet 53: 252-263

Fraser FC, Lytwyn A (1981) Spectrum of anomalies in the Meckel syndrome or: "Maybe there is a malformation syndrome with at least one constant anomaly". Am J Med Genet 9:67-73

Gschwend M, Levran O, Kruglyak L, Ranade K, Verlander PC, Shen S, Faure S, Weissenbach J, Altay C, Lander ES, Auerbach AD, Botstein D (1996) A locus for Fanconi anemia on $16 \mathrm{q}$ determined by homozygosity mapping. Am J Hum Genet 59:377-384

Hildebrandt F, Omram H (2001) New insights: nephronophthisismedullary cystic kidney disease. Pediatr Nephrol 16:168-176

Holmes LB, Driscoll SG, Atkins L (1976) Etiologic heterogeneity of neural-tube defects. N Engl J Med 294:365-369

Hsia YE, Bratu M, Herbordt A (1971) Genetics of the Meckel syndrome (dysencephalia splanchnocystica). Pediatrics 48:237247

Lander ES, Botstein D (1987) Homozygosity mapping: a way to map human recessive traits with the DNA of inbred children. Science 236:1567-1570

Lurie IW, Lazjuk GI, Korotkova IA, Cherstvoy ED (1991) The cerebro-reno-digital syndromes: a new community. Clin Genet 39:104-113

Mueller RF, Bishop DT (1993) Autozygosity mapping, complex consanguinity, and autosomal recessive disorders. J Med Genet 30:798-799

Müllenbach R, Lagoda PJL, Welter C (1989) An efficient saltchloroform extraction of DNA from blood and tissues. Trends Genet 5:391
Paavola P, Salonen R, Weissenbach J, Peltonen L (1995) The locus for Meckel syndrome with multiple congenital anomalies maps to chromosome 17q21-q24. Nat Genet 11:213-215

Perbal B, Martinerie C, Sainson R, Werner M, He B, Roizman B (1999) The C-terminal domain of the regulatory protein NOVH is sufficient to promote interaction with fibulin $1 \mathrm{C}$ : a clue for a role of $\mathrm{NOVH}$ in cell-adhesion signalling. Proc Natl Acad Sci USA 96: 869-874

Roume J, Genin E, Cormier-Daire V, Ma HW, Mehaye B, Attie T, Razavi-Encha F, Fallet-Bianco C, Buenerd A, Clerget-Darpoux F, Munnich A, Le Merrer M (1998) A gene for Meckel syndrome maps to chromosome. 11q13 Am J Hum Genet 63: 1095-1101

Salonen R (1984) The Meckel syndrome: clinicopathological findings in 67 patients. Am J Med Genet 18:671-689

Salonen R, Paavola P (1998) Meckel syndrome. J Med Genet 35: 497-501

Seller MJ (1978) Meckel syndrome and the prenatal diagnosis of neural tube defects. J Med Genet 15:462-465

Silva SR, Jeantry P (2000) Meckel syndrome. In: Callen PW (ed) Ultrasonography in obstetrics and gynecology, 4th edn. Elsevier, Amsterdam New York, pp 93-94

Simpson J L, Mills J, Rhoads, GG, Cunningham GC, Conley MR, Hoffman HJ (1991) Genetic heterogeneity in neural tube defects. Ann Genet 34:279-286

Smith CAB (1963) Testing for heterogeneity of recombination fraction values in human genetics. Ann Hum Genet 27:175182

Verloes A, Ayme S, Gambarelli D, Gonzales M, Le Merrer M, Mulliez N, Philip N, Roume J (1991) Holoprosencephaly-polydactyly ('pseudotrisomy 13') syndrome: a syndrome with features of hydrolethalus and Smith-Lemli-Opitz syndromes. A collaborative multicentre study. J Med Genet 28:297-303

Walpole IR, Goldblatt J, Hockey A, Knowles S (1991) DandyWalker malformation (variant), cystic dysplastic kidneys, and hepatic fibrosis: a distinct entity or Meckel syndrome? Am J Med Genet 39:294-298

Ward CJ, Hogan MC, Rossetti S, Walker D, Sneddon T, Wang X, Kubly V, Cunningham JM, Bacallao R, Ishibashi M, Milliner DS, Torres VE, Harris PC (2002) The gene mutated in autosomal recessive polycystic kidney disease encodes a large, receptor-like protein. Nat Genet 30:1-11

Young ID, Rickett AB, Clarke M (1986) Genetic analysis of malformations causing perinatal mortality. J Med Genet 23:58-63 